\title{
Fictive motion involves mental simulation in second language comprehension
}

\author{
Pan Ling ${ }^{1}$, Li zhiyi ${ }^{1}$ and Fan Jing ${ }^{1}$ \\ ${ }^{1}$ Henan University of Traditional Chinese Medicine, Zhengzhou, China
}

\begin{abstract}
Recent studies have confirmed that people produce mental simulation when processing sentences including literal motion, abstract motion or fictive motion. However, the doubt is whether EFL learners mentally simulate fictive motion during language comprehension as native English speaker did. The paper addressed the question with simulation time effects, one of the experimental methods in simulation semantics in one experiment made of 4 tasks. In each task, subjects read a short story --- slow versus fast scenario, easy versus difficult scenario and short versus long distance scenario, then made a timed decision whether the target fictive motion sentence related to the story or not. The results are that the response latency in different scenarios is significant. Thereby we conclude that EFL learners activates mental simulation in the same way as native English speaker when processing sentences involved the fictive motion.
\end{abstract}

Keywords: mental simulation, fictive motion sentence, EFL learner, second language comprehension

\section{Literature Review}

\subsection{Mental Simulation}

Processing language uses perceptual and motor areas of the brain, not only to perceive written characters or spoken sounds, but also to extract meaning from utterances. When people process language that describes perceivable scenes or performable actions, they display selective activation of perceptual and motor systems. (Pulvermuller, Haerle, \& Hummel, 2001; Hauk, Johnsrude, \& Pulvermuller, 2004). Mental simulation is the internal enactment or reenactment of perceptual, motor, or affective experiences (Barsalou, 1999). Mental simulation may be static or dynamic, and this term is often used interchangeably in the literature with mental imagery. Mental simulation is produced by brains structures specific to the relevant modality; motor simulation uses motor areas, down to the specific regions that control simulated effectors (Porro et al., 1996; Lotze et al., 1999; Ehrsson, Geyer, \& Naito, 2003; Willems \& Hagoort, 2007).

\subsection{Fictive Motion}

Does mental simulation arises with fictive motion --- an implicit type of motion, namely:

The road runs along the coast

The trail goes from Canada to Mexico

This type of sentence communicates a stationary situation even though it features a motion verb (e.g., run or go) and describes a scene that involves motion. Thus, unlike the literal uses of motion verbs, such as John runs along the coast, fictive motion sentences communicate no change of state (Matlock, 2011). This sort of language is common across languages, including English, Spanish, and Japanese, and it often occurs when people are describing physical space (Matlock, 2004; Matsumoto, 1996). 


\section{Methodology}

\subsection{Participants And Material}

Participants in the present study are 35 non-English major postgraduate of Dalian University of Technology, who are EFL learners. They are randomly selected with the different levels of the English ability who have passed the CET 6.

The experiment stimuli includes 4 pairs of stories(slow vs. fast scenario, easy vs. difficult scenario and short vs. long distance senario) and corresponding fictive motion sentences. The 16 stories are about protagonist traveling through outdoor region, generally concerns 4 main parts: (1) the region (such as the size or dimension), (2) a traversable path (such as a road), (3) a moving protagonist and (4) travel time.

\subsection{Procedure}

The similation time effects adopted in this paper is a straightforward way to investigate the relation between real and simulated time, designed by Matlock (2004). In each task, participants read a story about a protagonist traveling a spatial region and then decided whether a target fictive motion sentence related to the story. The principle is that the reader would first construct a spatial model while reading the short story. In constructing the model, they would simulate motion analogous to the way they would perceive or perform motion along a real path. Thus when deciding whether the target fictive motion sentence related to the story, the subject would retrieve the information they had constructed. If fictive motion processing involves mental simulation, there would be differences in response time. For instance, if fictive motion processing involves simulation, decision times for fictive motion sentences should be longer after the participants had thought about long- distance travel.

\section{Results and Discussion}

\subsection{Data Analysis}

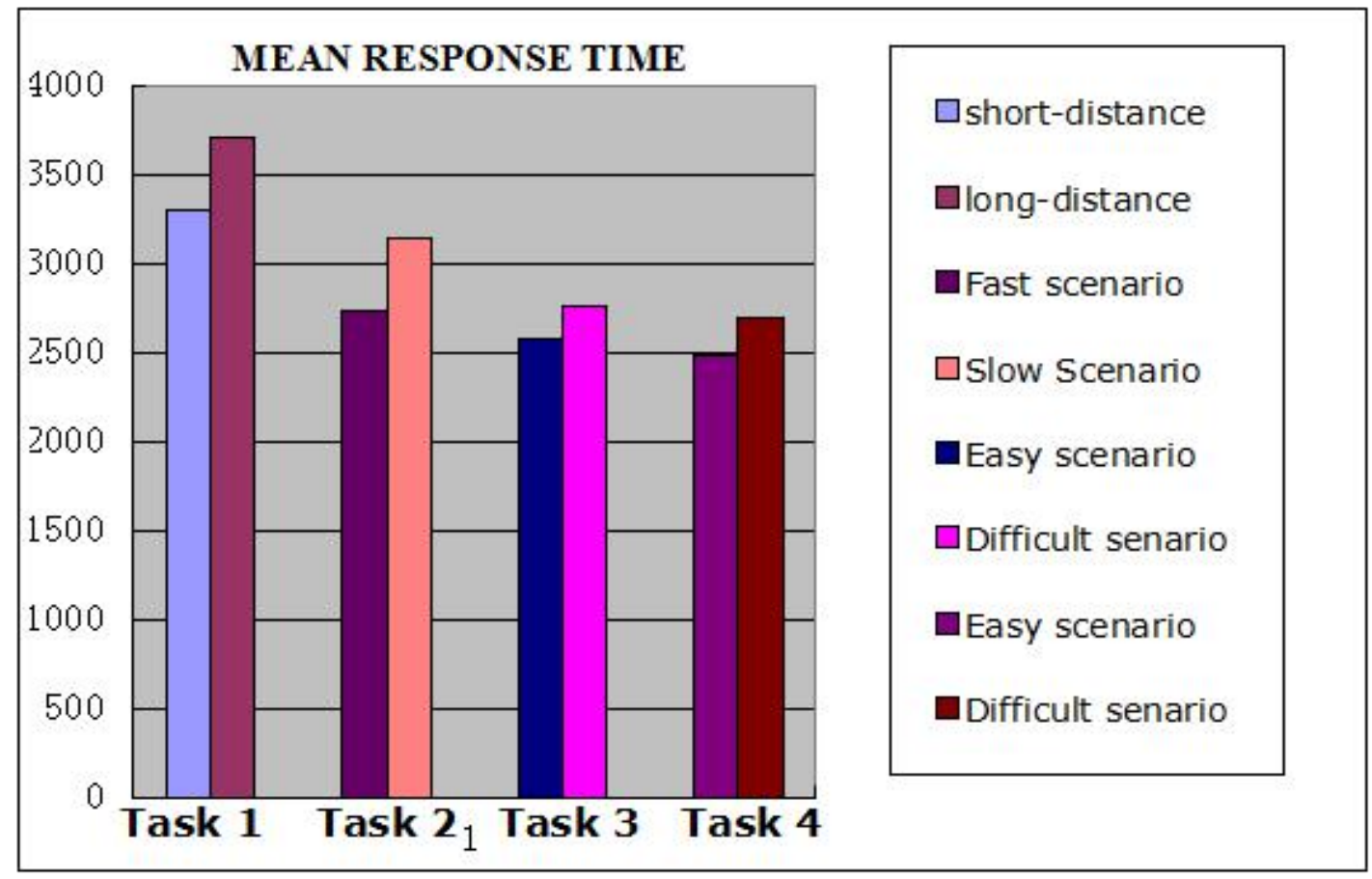

Table 1: Mean Response Time 
In this experiment, scores above $8000 \mathrm{msec}$ and below $500 \mathrm{msec}$ are removed because they refected an unreasonable amount of time to make decision about a critical sentence. Only scores for correct decisions are analyzed.

In the 4 tasks, fictive motion decision times were influenced by the way motion or spatial configuration in Task 4 had been described. Response time was shorter after short distance (Task 1), fast motion (Task 2), and uncluterred terrain (Task 3, Task 4). Overall, the results sggest that fictive motion sentence processing involves mental simulation.

The possible explanation is that the EFL Learner do also constructed a spatial model and imagined movement through that model whlie reading about the travel as the native Englsih speaker did. They simulated movement along the path in a way that was consistent with the protagonist's actual movement along that path. For instance, in Task 1, when subject attempt to understand and decide whether Road 49 crosses the desert related to the story, people simulated motion along the road they had imagined. When they had thought about a protagonist traveling a long distance on that road, the fictive sentence about Road 49 took longer to process than it did with a short distance.

To sum up, EFL learners mentally simulate fictive motion during second language comprehension as native English speaker did.

\section{Conclusion}

In sum, the paper explored the relationship between thought about motion and sentence about motion --- especially figurative sentence about motion. The results suggest that EFL learners do also simulate motion when processing fictive motion sentences such as The road runs along the coast. The effect is robust and taking place under different circumstances. The findings go against purely amodal or symbolic approach to language. What's more important, the results have profound implications for research on figurative language and thought, because it suggests that the mental simulation of motion occurs not just in literal thought and language about motion, but also in figurative thought and language about motion as well.

\section{References}

[1] Barsalou, L.W. Simulation, situated conceptualization, and prediction [J]. Philosophical Transactions of the Royal Society of London: Biological Science, 2009, 364, 1281-1289.

[2] Bergen, B, Chang, N. Embodied Construction Grammar in Simulation-Based Language Understanding [M] // In OSTMAN J, FRIED M. Construction Grammars: Cognitive grounding and theoretical extensions. Oxford: Oxford University Press, 2005: 96-126.

[3] Bergen.B. Experimental methods for simulation semantics. In Monica Gonzalez, Irene Mittelberg, Seana Coulson, \& Michael J.Spivey (eds.). Methods in cognitive linguistics, (2007).

[4] Engelen, J. A.A, Bouwmeester, S,de Bruin, A. B. H. et al. Perceptual simulation in developing language comprehension [J]. Journal of Experimental Child Psychology, 2011, 110 (4), 659-675.

[5] Kemmerer, D. Cognitive Neuroscience of Language [M]. New York: Psychology Press, 2015.

[6] CONNELL L. Representing object colour in language comprehension [J]. Cognition, 2007, 102, 476-485.

[7] Matlock, T. :The conceptual motivation of fictive motion. In G. Radden \& R. Dirven (eds), Studies in linguistic motivation. (Berlin: Moutou de Gruyter.2004.) 
[8] Talmy, L. Toward a cognitive semantics: conceptual structuring systems. (Cambridge. MA: MIT Press,2004)

[9] Kaschak M.P, Madden, C, T. J, et al. Perception of motion affects language processing [J]. Cognition, 2005, 94, B79-B89.

[10] Pulvermuller, F. Grounding language in the brain [M] // In De Vega, M, Graesser, A, Glenberg, A. Symbols, embodiment, and meaning. Oxford: Oxford University Press, 2008: 85-116. 